\title{
Analyses and treatment of simultaneous bi-lineage malignancies of myeloid leukemia and lymphoma: Two case reports and a literature review
}

\author{
XIAORUI FU ${ }^{1,2^{*}}$, YUFENG SHANG ${ }^{1,2^{*}}$, LEI ZHANG ${ }^{1,2}$, LING LI $^{1,2}$, XIN LI $^{1,2}$, \\ XINHUA WANG ${ }^{1,2}$, ZHENCHANG SUN ${ }^{1,2}$ and MINGZHI ZHANG ${ }^{1,2}$ \\ ${ }^{1}$ Department of Oncology, The First Affiliated Hospital of Zhengzhou University; \\ ${ }^{2}$ Lymphoma Diagnosis and Treatment Center, Zhengzhou, Henan 450002, P.R. China
}

Received November 30, 2017; Accepted September 6, 2018

DOI: $10.3892 / \mathrm{ol} .2018 .9447$

\begin{abstract}
The present study reports two cases of concurrently diagnosed T-lymphoblastic lymphoma (T-LBL) and chronic myeloid leukemia (CML). The literature review revealed that myeloid leukemia may appear secondary to Hodgkin lymphoma or non-Hodgkin lymphoma. However, simultaneous bi-lineage hematologic malignancies are rarely seen and the prognosis is worse than single lineage lymphoma or myeloid leukemia. There were no standard therapies. All simultaneous bi-lineage malignancies of myeloid leukemia and lymphoma reported in Pubmed were combined with the present two cases, to analyses its pathogenesis, features and treatment. It was concluded that the prognosis of bi-lineage hematologic malignancies was poor, however allogeneic hematopoietic stem cell transplantation could improve survival $(\mathrm{P}=0.033)$.
\end{abstract}

\section{Introduction}

Lymphoma, classified into Hodgkin lymphoma (HL) and non-Hodgkin lymphoma (NHL) with various subtypes respectively, originates from precursor cells in primary lymph organs or from mature cells located in the peripheral lymphoid organs, arising from a clone expansion of B-or-T lymphocytes transformed during the pathways of lymphocyte differentiation $(1,2)$. Chronic myeloid leukemia (CML) and acute myeloid leukemia (AML) are clonal expansion of hematopoietic progenitor cells characterized by exaggerated

Correspondence to: Professor Mingzhi Zhang, Department of Oncology, The First Affiliated Hospital of Zhengzhou University, 1 Jianshe Roud, Zhengzhou, Henan 450002, P.R. China

E-mail: mingzhi_zhang1@163.com

${ }^{*}$ Contributed equally

Key words: concurrent bi-lineage hematologic malignancies, myeloid leukemia, lymphoma, pathogenesis, prognosis, allogeneic hematopoietic stem cell transplantation proliferation of granulocytic lineage while CML undergoes a chronic course relatively. Lymphoma and myeloid leukemia are different malignancy originating from two lineages and possess disparate cytogenetic, cell phenotype and biological process. Generally, lymphoma combining with myeloid leukemia is rarely seen except when CML in blast crisis with a bare possibility occurs acute lymphocyte mutation. It is more rarely seen that simultaneous bi-lineage malignancies without history treatment at initial diagnosis. Shen et al reviewed 24 patients with CML and T-lymphoblastic cell NHL (T-LBL) in the lymph node between 1980 and 2016, but most of those patients experienced chronic history of CML followed by T-LBL afterwards (3). Some scholars reported NHL or HL developing into leukemia during remission or treatment (4-7). The cause about the bi-lineage hematologic malignancies is unclear yet. Lam et al analysedrisk factors ofsecondary acute myeloid leukemia/myelodysplastic syndrome among survivors of NHL (6). Eichenauer et al reported therapy-related acute myeloid leukemia and myelodysplastic syndromes in patients with HL (4). To our best knowledge, the therapy-related secondary tumor has been frequently reported in patients who received various chemotherapy regimens or radiotherapy or transplantation, however, there is no systematic summary to individual cases about simultaneous bi-lineage hematologic malignancies without previous therapy. So, we summary simultaneous lymphoma and myeloid leukemia through literature searching on PubMed (ncbi.nlm.nih.gov/pubmed) with the term 'myeloid leukemia' or 'myelogenous leukemia' combined with 'lymphoma' and 'simultaneous' or 'concurrent' or 'coinstantaneous' or 'co-existence' to explore the features, prognosis and treatment. In the meantime, we present our two cases diagnosed with concurrent T-LBL and CML.

\section{Patients and methods}

Case report

Case 1. On April 27, 2009, a 43-year-old Chinese male was admitted hospital because of finding a cervical mass for 10 days. On physical examination, multiple enlarged lymph nodes no bigger than $4 \times 2 \mathrm{~cm}$ were found in bilateral cervical, submandibular and submental region. Other physical 
findings were unremarkable. The chest and abdomen CT scan was normal except splenomegaly. A complete blood count revealed leucocyte count $43.81 \times 10^{9} / 1$ with $3.6 \%$ blasts, $7.2 \%$ promyelocytes, erythrocyte count $4.45 \times 10^{12} / 1$, hemoglobin level $136.0 \mathrm{~g} / \mathrm{l}$, platelet count $123 \times 10^{9} / 1$, aneutrophils count $25.06 \times 10^{9} / 1, \beta$-microglobulin level $2.01 \mathrm{mg} / 1$, lactate dehydrogenase (LDH) level $382 \mathrm{U} / 1$. A subsequent bone marrow aspiration showed malignant proliferation of the myeloid Department with myeloblasts $>10 \%$ and that ratios of neutrophilic myelocyte, metamyelocyte and segmented neutrophil all increased. The chromosome indicated 46,XY,t $(9,22)$. The FISH test for BCR/ABL was positive with a rate of $7 \%$. Biopsy of the right cervical lymph node reveal T-LBL with lymphoma cells expressing CD3, CD4, CD45, TdT (terminal deoxynucleotidyl transferase), but negative for CD20, Pax-5, CD79a, ALK, MPO, Ki-67 level is 90\% (Fig. 1). So ultimate diagnosis was T-LBL in stage II according to the Ann Arbor classification, the IPI (8) being 2, combining with CML in blastic phase. The patient was treated with Hyper-CVAD A (cyclophosphamide, vincristine, adriamycin and dexamethasone) scheme one cycle and imatinib $600 \mathrm{mg}$ qd. Then MOAP (mitoxantrone, vincristine, arabinoside and prednisone) five cycles and intrathecal injection four times. The patients obtained nearly complete remission with bone marrow blasts and promyelocytes reduced to $0.4 \%$. Afterwards the patient accepted haploidentical hematopoietic stem cell transplantation on December 15, 2009. Until now (June 2017), the patient had obtained continuous complete remission (CR) for over 8 years.

Case 2. On December 12, 2012, a 44-year-old Chinese male was complained of finding a cervical mass with exacerbation for more than 20 days. On physical examination, several enlarged lymph nodes were observed in the bilateral neck, right collarbone and axillary. In addition, the patient's left pharyngeal cavity was inflamed with a random-shaped neoplasm. A complete blood test: leucocyte count $25.1 \times 10^{9} / 1$, erythrocyte count $3.34 \times 10^{12} / 1$, hemoglobin $103.0 \mathrm{~g} / 1$, platelet $123 \times 10^{9} / 1$, neutrophils $19.6 \times 10^{9} / 1, \beta$-microglobulin $2.0 \mathrm{mg} / 1$, LDH $638 \mathrm{U} / 1$. the blasts, promyelocytes and metamyelocytes appeared in the peripheral blood. Bone marrow analysis revealed granulocyte proliferation with hyperactivity, blasts and promyelocytes accounted for $7.6 \%$ (Figs. 2 and 3). The fluorescence in situ hybridization (FISH) test for BCR/ABL was positive with a rate of $70.2 \%$. So, CML was diagnosed. The biopsy of left cervical lymph node conformed to T-LBL with lymphoma cells expressing CD20, CD3, CD21 (part of the FDC were destroyed), CD10, Bcl-2, TdT, CD43, CD7, CD2 and CD34, while MPO, CD30, ALK, EMA were negative (Fig. 4). The Ki-67 labeling index was 50 to $60 \%$. According to these findings, a preliminary diagnosis was: CML in chronic phase, mydoid sarcoma (MS) and T-LBL. Without treatment, the patient left the hospital. On March 2, 2013, the patient re-hospitalized. Repeated examination was the same as it was before except lymph nodes bigger. From March 5, 2013 to July 8, 2013, the patient was treated with Hyper-CVAD $\mathrm{A}$ and $\mathrm{B}$ alternately for six cycles, and intrathecal injection for 11 times and reached partial remission, but he didn't take imatinib for lack of money during this period. Since August 2, 2013, two cycles of Hyper-CVAD B were given again with taking imatinib $400 \mathrm{mg}$ qd. However the disease progressed. The patient did not continue treatment later, and succumbed on March 12, 2014.

Summary to the two cases. Our two cases were admitted because of a cervical mass, and then found superficial lymphadenopathy with the peripheric blood leucocyte soaring. Biopsy of the cervical lymph node prove T-LBL depending on immunohistochemistry and typical morphology. The FISH test for BCR/ABL of bone marrow was positive with rates of 7 and $70.2 \%$. So the two cases were diagnosed T-LBL with CML finally. In terms of treatment, case 1 experienced durable complete remission until present through chemotherapy combining imatinib and then haploidentical hematopoietic stem cell transplantation. However the second patient soon died after chemotherapy and taking imatinib.

Methods. We here summary all concurrent myeloid leukemia and lymphoma from 1976 to present (Table I) to analyze the features, prognosis and treatment. Statistical analyses were performed using IBM SPSS statistics software, version 21.0 (IBM Corp., Armonk, NY, USA) and GraphPad Prism 6 (GraphPad Software, Inc., La Jolla, CA, USA). OS distributions were estimated using the Kaplan-Meier curve analysis, time-to-event distributions were compared using the log-rank test and two-tailed significance-level of 0.05 was considered statistically significant.

Patient characteristics. From the statistics we conclude that the patients ranged between 9 and 82 years old (median, 43 years). The male/female ratio was $2.83: 1$ (17:6). 16 patients were involved lymphadenectasis in bilateral cervical, submandibular, submental and mediastinal region accompanying fatigue and fever, among of which skull or liver or spleen or skin lesions was involved in 1 patient, 2 patients, 4 patients and 1 patient respectively. 2 patients was involved spleen without lymphadenectasis. Abe et al (9) reported a patient was admitted in the hospital because of progressive jaundice with MALT lymphoma in gallbladder and AML in marrow. Van Crombrugge et al (10) reported a patient referred to hospital because of severe headache and progressive facial pain and ultimately diagnosed NK cell lymphoma in sinonasal and AML. The remaining patients were failed to get information. We sum up total cases of different simultaneous lymphoma and myeloid leukemia (Fig. 5). Simultaneous AML and lymphoma is more than simultaneous CML and lymphoma being 14 and 10 respectively. The number of simultaneous T-cell non-Hodgkin-lymphoma is 15 and the number of simultaneous B-cell non-Hodgkin-lymphoma is 5 . For the treatment, 10 patients were treated with chemotherapy, 2 patients were treated with chemotherapy andradiotherapy, 2 patients were treated with with single imatinib, 5 patients were treated with with chemotherapy and transplantation and 1 patient was untreated.

Survival and statistical analysis. In the 24 patients, 21 patients were available to analyze survival and the median survival was 15 months (Fig. 6). We performed univariate analysis to evaluate the prognostic factors. There was no statistical significance for sex $(\mathrm{P}=0.301)$ and for age $(\mathrm{P}=0.168)$ which was set 


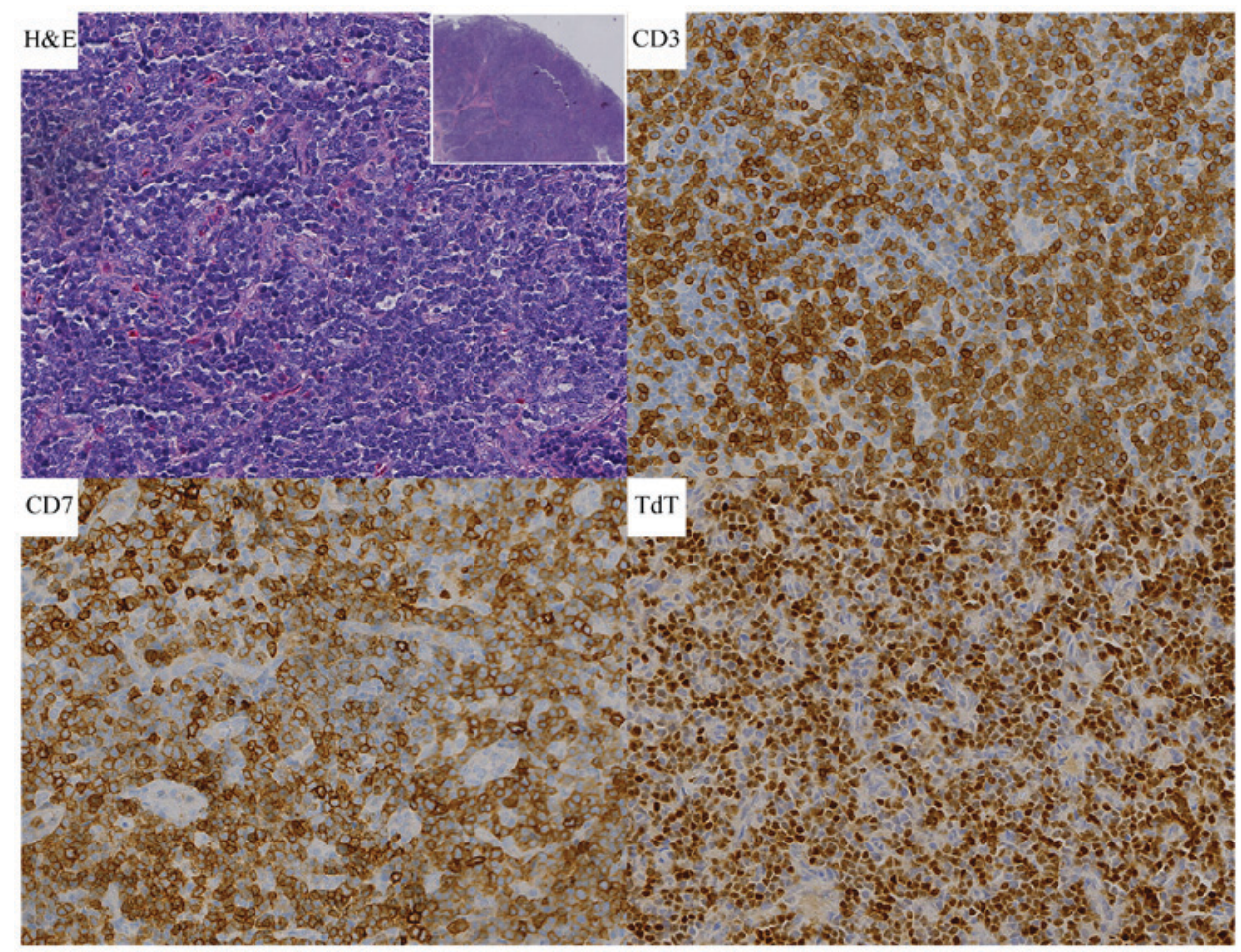

Figure 1. Case 1 histological findings. H\&E stain of cervical lymph node section showing destruction of normal structure (magnification, $\mathrm{x} 40$ ) and numerous lymphoblastic lymphoma cells (magnification, x400). Lymph node with T-lymphoblastic cell non-Hodgkin's lymphoma stained with CD3, CD7 and TdT (magnification, $\mathrm{x} 400$ ). $\mathrm{CD}$, cluster of differentiation; H\&E, hematoxylin and eosin.

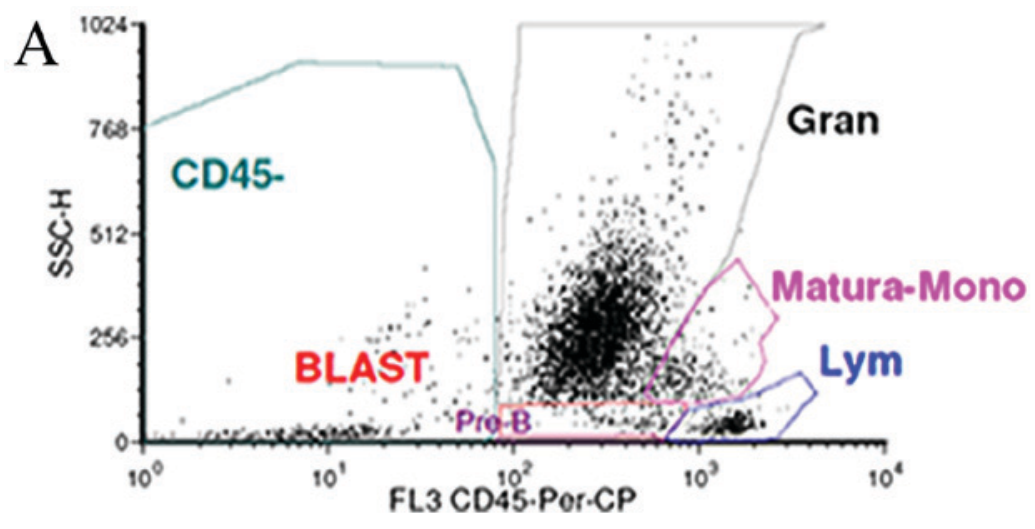

\begin{tabular}{|c|c|c|}
\hline \multicolumn{3}{|c|}{ COss-SSC Gating } \\
\hline QAST & $252 \%$ & $w \otimes C$ \\
\hline Waturatuono & $4.79 \%$ & Wo \\
\hline$a n$ & 8685\% & $W \otimes C$ \\
\hline tymph & $6.50 \%$ & 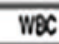 \\
\hline 910.8 & $0.00 \%$ & $w x$ \\
\hline coss & $5.12 \%$ & LWE \\
\hline MNC & SWA & LWVE \\
\hline$W \otimes C$ & NWF & UWE \\
\hline UNE & \multicolumn{2}{|c|}{ S200\% All Colls } \\
\hline Potabcolls & 80000 & tube \\
\hline
\end{tabular}
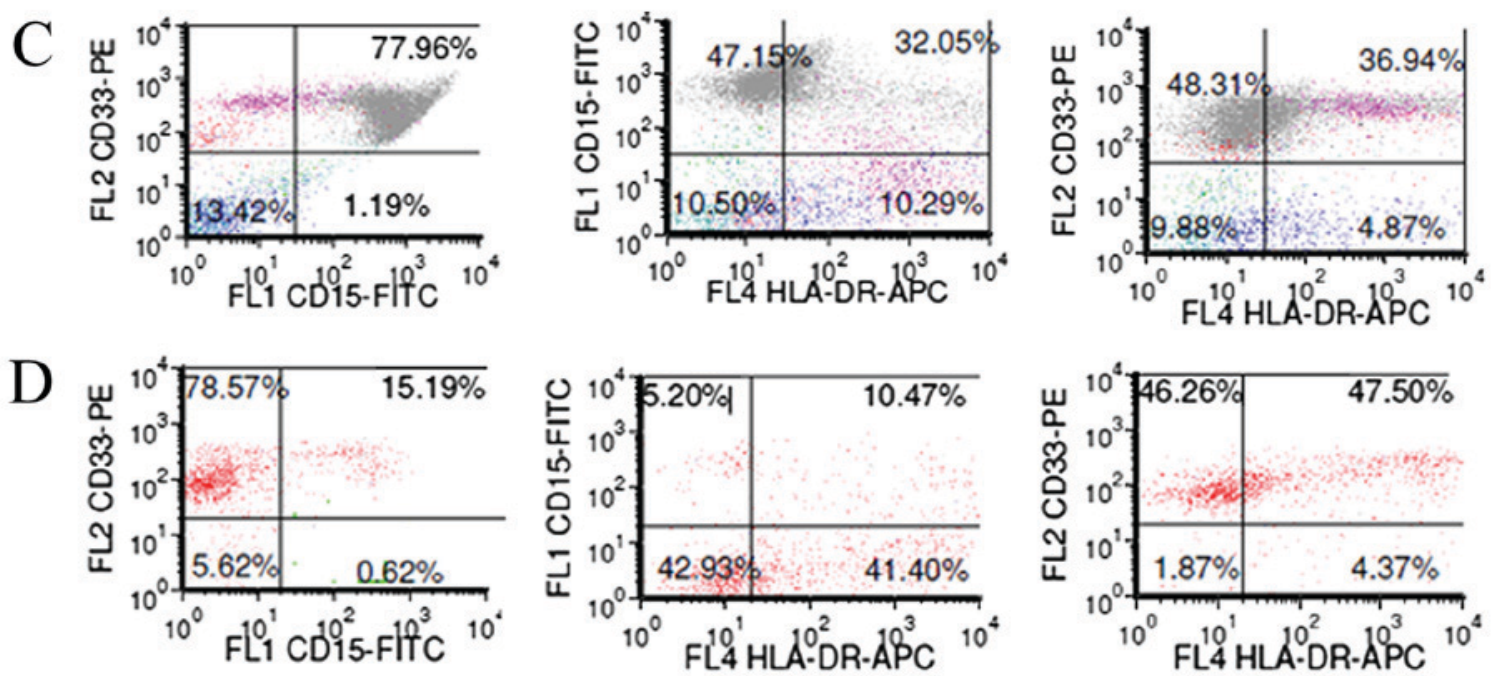

Figure 2. Flow cytometer analysis of bone marrow aspirate. (A) CD45/SSC gating and (B) data presentation. (C) The percentage of granulocyte increase and express CD33, CD15, HLA-DR+. (D) Blasts are CD33+, CD15+ and HLA-DR+. CD, cluster of differentiation. 

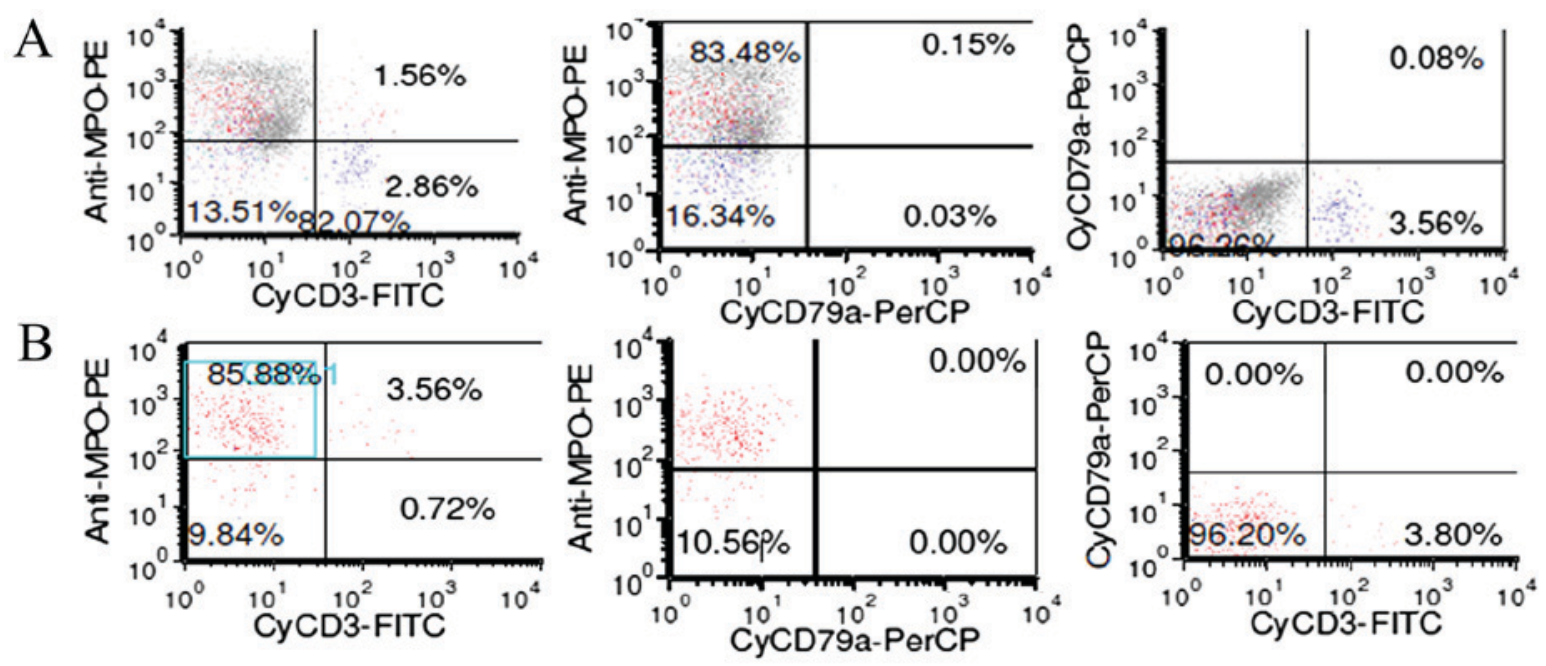

Figure 3. Intracellular antigen determination. MPO + occupy (A) $83.63 \%$ of live and (B) $89.44 \%$ of blast.

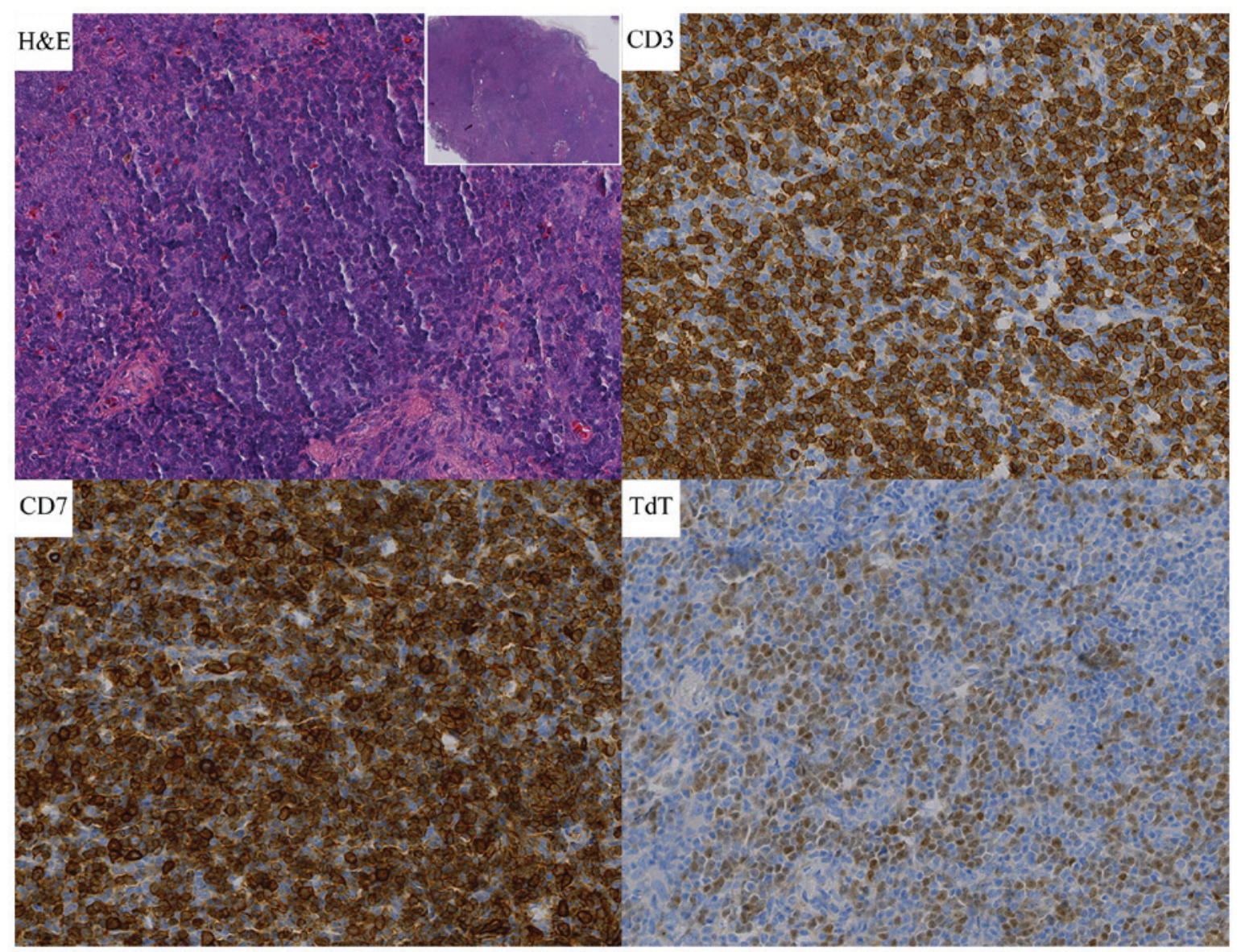

Figure 4. Case 2 histological findings. H\&E stain of cervical lymph node section showing destruction of normal structure (magnification, $\mathrm{x} 40$ ) and numerous lymphoblastic lymphoma cells (magnification, x400). Lymph node with T-lymphoblastic cell non-Hodgkin's lymphoma stained with CD3, CD7 and TdT (magnification, $\mathrm{x} 400)$. CD, cluster of differentiation; H\&E, hematoxylin and eosin.

43.5 years as cut-off based on the ROC curve. There was no survival difference between B cell lymphoma companying myeloid leukemia and $\mathrm{T}$ cell lymphoma companying myeloid leukemia ( $\mathrm{P}=0.158$; Fig. 7A). Similarly, no survival difference was received between AML companying lymphoma and CML companying lymphoma ( $\mathrm{P}=0.167$; Fig. 7B). Because of concurrent T-LBL and myeloid leukemia being relatively common, we performed statistical analysis between T-LBL combining CML and T-LBL combining AML, but there was no statistical difference in survival ( $\mathrm{P}=0.485$; (Fig. 7C). For the treatment, chemotherapy together with transplantation are superior to other treatment without transplantation ( $\mathrm{P}=0.033$; Fig. 7D). The median survival was unreached for patients with transplantation and 11 months for those without transplantation. 
Table I. Review of patients with myeloid leukemia and lymphoma from 1976 to present.

\begin{tabular}{|c|c|c|c|c|c|c|c|c|}
\hline Case & $\begin{array}{l}\text { First author, } \\
\text { year }\end{array}$ & Sex & $\begin{array}{c}\text { Age } \\
\text { (years) }\end{array}$ & Involvement sites & Initial diagnosis & Treatment & $\begin{array}{l}\text { Follow-up } \\
\text { (months) }\end{array}$ & (Refs.) \\
\hline 1 & Kapadia, 1976 & $\mathrm{~F}$ & 64 & $\begin{array}{l}\text { Lymph nodes and } \\
\text { liver and marrow }\end{array}$ & NHL-PDL and AML & CTx & 11 & $(27)$ \\
\hline 2 & Youness, 1978 & $\mathrm{M}$ & 67 & Spleen and marrow & NHL-PDL and AML & CTx & 5 & (28) \\
\hline 3 & Ramji, 1988 & $\mathrm{NC}$ & $\mathrm{NC}$ & $\mathrm{NC}$ & T-NHL and CML & $\mathrm{NC}$ & $\mathrm{NC}$ & (29) \\
\hline 4 & Ohtsu, 1988 & M & 49 & $\mathrm{NC}$ & ATL and AML & $\mathrm{NC}$ & 6 & $(30)$ \\
\hline 5 & Tsukasaki, 1995 & $\mathrm{~F}$ & 36 & $\mathrm{NC}$ & ATL and AML & $\mathrm{NC}$ & $30^{\mathrm{b}}$ & $(11,16)$ \\
\hline 6 & Abe, 1999 & $\mathrm{~F}$ & 82 & $\begin{array}{l}\text { Gallbladder } \\
\text { and marrow }\end{array}$ & MALT and AML & Untreated & 3 & (9) \\
\hline 7 & Morales, 1999 & M & 63 & $\begin{array}{l}\text { Lymph nodes and } \\
\text { marrow }\end{array}$ & T- NHL and CML & CTx & $\mathrm{NC}$ & $(31)$ \\
\hline 8 & Montefusco, 2001 & M & 64 & Spleen and marrow & NHL-LG and AML & $\begin{array}{l}\text { CTx and } \\
\text { hydroxyurea }\end{array}$ & 25 & $(32)$ \\
\hline 9 & $\begin{array}{l}\text { Zámecníková, } \\
2002\end{array}$ & $\mathrm{M}$ & 34 & $\begin{array}{l}\text { Lymph nodes and } \\
\text { liver and marrow }\end{array}$ & DLBCL and CML & CTx and RT & 4 & (2) \\
\hline 10 & $\mathrm{Au}, 2003$ & $\mathrm{M}$ & 67 & $\begin{array}{l}\text { Mediastinal lymph } \\
\text { nodes and marrow }\end{array}$ & B-NHL and CML & $\begin{array}{l}\text { CTx and RT and } \\
\text { hydroxyurea }\end{array}$ & $144^{\mathrm{b}}$ & (33) \\
\hline 11 & Lamb, 2005 & $\mathrm{M}$ & 9 & $\begin{array}{l}\text { Lymph nodes and } \\
\text { spleen and marrow }\end{array}$ & T-LBL and AML & $\begin{array}{l}\text { CTx and allo- } \\
\text { HSCT }\end{array}$ & $48^{\mathrm{b}}$ & (34) \\
\hline 12 & Metzgeroth, 2007 & $\mathrm{M}$ & 58 & $\begin{array}{l}\text { Lymph nodes and } \\
\text { spleen and marrow }\end{array}$ & T-NHL and AEL & Imatinib & $18^{\mathrm{b}}$ & (12) \\
\hline 13 & Capovilla, 2008 & $\mathrm{M}$ & 33 & $\begin{array}{l}\text { Lymph nodes and } \\
\text { spleen and marrow }\end{array}$ & T-LBL and CEL & Imatinib & $12^{\mathrm{b}}$ & $(35)$ \\
\hline 14 & $\mathrm{Li}, 2011$ & M & 12 & $\begin{array}{l}\text { Lymph nodes and } \\
\text { marrow }\end{array}$ & T-LBL and AML & CTx & 4 & (36) \\
\hline 15 & Chang, 2012 & $\mathrm{M}$ & 41 & $\begin{array}{l}\text { Lymph nodes and } \\
\text { skin lesions and } \\
\text { marrow }\end{array}$ & T-LBL and AML & $\begin{array}{l}\text { CTx and allo- } \\
\text { HSCT }\end{array}$ & $14^{\mathrm{a}}$ & (13) \\
\hline 16 & Sharkunov, 2012 & $\mathrm{~F}$ & $\mathrm{~N}$ & $\mathrm{NC}$ & HL and CML & CTx and imatinib & $\mathrm{NC}$ & (37) \\
\hline 17 & Wan, 2012 & $\mathrm{M}$ & 43 & $\begin{array}{l}\text { Lymph nodes and } \\
\text { marrow }\end{array}$ & T-LBL and CML & $\begin{array}{l}\text { CTx and allo- } \\
\text { HSCT }\end{array}$ & $19^{\mathrm{b}}$ & $(38)$ \\
\hline 18 & $\begin{array}{l}\text { VanCrombrugge, } \\
2012\end{array}$ & M & 47 & $\begin{array}{l}\text { Sinonasal and } \\
\text { adjacent and marrow }\end{array}$ & $\begin{array}{l}\text { NK-NHL } \\
\text { IVB and AML }\end{array}$ & CTx & $\begin{array}{l}\text { Approximately } \\
2 \text { months }\end{array}$ & (10) \\
\hline 19 & Kunitomi, 2014 & $\mathrm{~F}$ & 62 & $\begin{array}{l}\text { Lymph nodes and } \\
\text { marrow }\end{array}$ & $\begin{array}{l}\mathrm{EBV}(+) \mathrm{DLBCL} \\
\text { and AML }\end{array}$ & CTx & 34 & (39) \\
\hline 20 & Dong, 2016 & M & 25 & $\begin{array}{l}\text { Lymph nodes and } \\
\text { marrow }\end{array}$ & T-LBL and AML & $\begin{array}{l}\text { CTx and allo- } \\
\text { HSCT }\end{array}$ & $34^{\mathrm{b}}$ & (40) \\
\hline 21 & Shen, 2016 & M & 28 & $\begin{array}{l}\text { Lymph nodes and } \\
\text { spleen and marrow }\end{array}$ & T-LBL and CML & CTx & $\begin{array}{l}3 \text { months and } \\
\text { lost follow-up }\end{array}$ & (3) \\
\hline 22 & Dai, 2017 & $\mathrm{~F}$ & 37 & $\begin{array}{l}\text { Lymph nodes and } \\
\text { skull and marrow }\end{array}$ & DLBCL and AML & $\begin{array}{l}\mathrm{CTx} \\
\text { andimatinib }\end{array}$ & $\begin{array}{l}\text { Approximately } \\
2 \text { months }\end{array}$ & (41) \\
\hline 23 & Our case & M & 43 & $\begin{array}{l}\text { Lymph nodes and } \\
\text { marrow }\end{array}$ & T-LBL and CML & $\begin{array}{l}\text { CTx and allo- } \\
\text { HSCT andimatinib }\end{array}$ & $98^{\mathrm{b}}$ & \\
\hline 24 & Our case & M & 44 & $\begin{array}{l}\text { Lymph nodes and } \\
\text { marrow }\end{array}$ & T-LBL and CML & CTx and imatinib & 15 & \\
\hline
\end{tabular}

${ }^{a}$ The patient succumbed of GVHD and related infections, but he remained free from both malignancies for at least 11 months after transplantation. ${ }^{\text {b}}$ The OS was longer that corresponding time and the death was not observed. AEL, acute eosinophilic leukemia; AML, acute myeloid leukemia; ATL, adult T-cell leukemia; B-NHL, B-cell non-Hodgkin-lymphoma; CEL, chronic eosinophilic leukemia; CML, chronic myeloid leukemia; DLBCL, diffuse large B cell lymphoma; MALT, mucosa-associated lymphoid tissue; NHL-LG, non-Hodgkin lymphoma low-grade; PDL, poorly differentiated lymphoma; T-NHL, T-cell non-Hodgkin-lymphoma. CTx, chemtherapy; RT, radiotherapy; $\mathrm{CR}$, complete remission; GVHD, graft-versus-host disease, allo-HSCT, allogeneic hematopoietic stem cell transplantation; NC, not clear; (+), positive. 


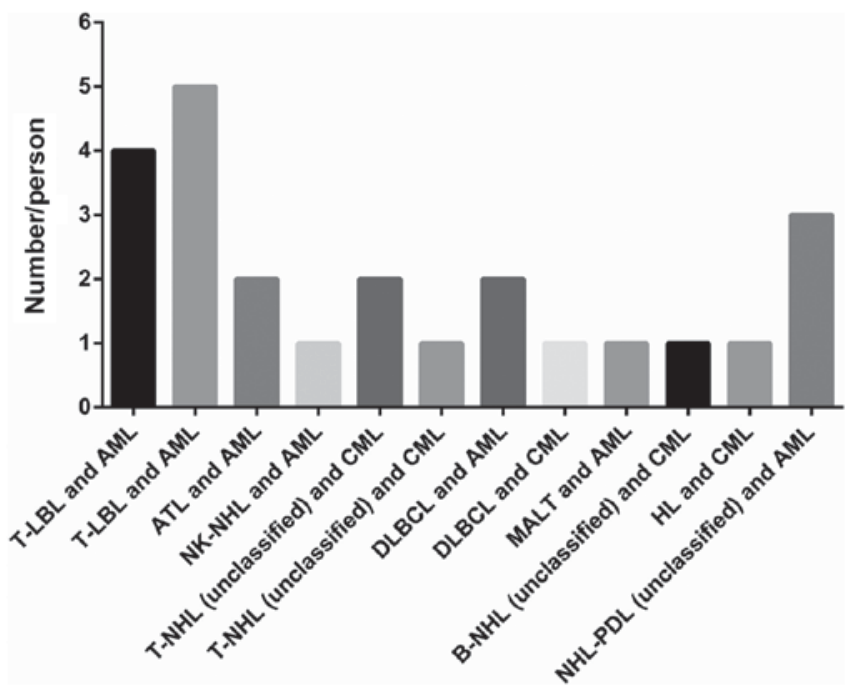

Figure 5. Summary of cases of simultaneous lymphoma and myeloid leukemia. T-LBL, T-lymphoblastic lymphoma; ATL, Adult T-Cell Leukemia/Lymphoma; CML, chronic myeloid leukemia; T-NHL, T-cell non-Hodgkin-lymphoma; MALT, mucosa-associated lymphoid tissue; PDL, poorly differentiated lymphoma; DLBCL, diffuse large B cell lymphoma; HL, Hodgkin lymphoma.

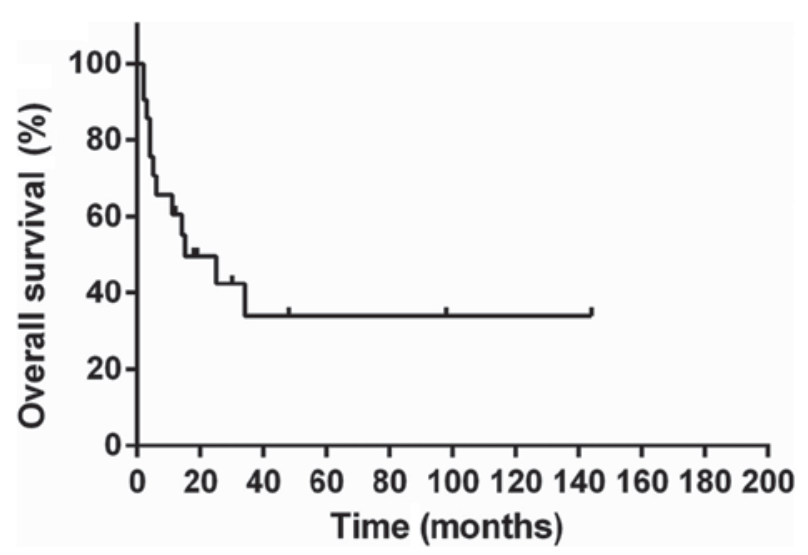

Figure 6. Overall survival for 21 patients with simultaneous bi-lineage malignancies. The median survival was 15 months.

\section{Discussion}

Lymphoma and myeloid leukemia derive from different tumour cells, and they mostly happen alone. It was frequently reported that secondary or therapy-related hematologic malignancies, but co-concurrent bi-lineage hematologic malignancies are really rare. We present two cases simultaneous T-LBL and CML and then reviewed all cases available to collect from Pubmed. The characteristics are as follows: The simultaneous neoplasm tended to occur in young to old with a good majority in male. Patients are mostly admitted in the hospital because of enlarged lymph nodes accompanying fatigue, fever and splenomegaly. Simultaneous HL and myeloid leukemia is extremely rare and only one case was reported. Simultaneous AML and lymphoma is more commonly seen than simultaneous CML and lymphoma. Simultaneous T cell lymphoma and myeloid leukemia is more thansimultaneous B cell lymphoma and myeloid leukemia. The number of simultaneous T-LBL and myeloid leukemia is maximum than any other subtypes. There is no statistical difference in survival for different bi-lineage malignancy.

However, due to the rarity of patients with bi-lineage tumors, little is known concerning the pathogenesis. Early in 1998, Tsukasaki et al reported the possible association between adult T-cell leukemia/lymphoma and acute myeloid leukemia. One of the possible mechanism is that immune system is compromised severely in Adult T-Cell Leukemia/Lymphoma (ATL) patients which results in the occurrence of AML. The other possible explanation for the association of ATL and AML is that growth factors such as M-CSF, G-CSF, and GM-CSF produced by the ATL cells support the growth of the AML cells (11). Metzgeroth et al demonstrated the association of the FIP1L1-PDGFRA fusion gene with lymphoblastic T-NHL and eosinophilia-associated acute myeloid leukemia (12). Chang et al (13) and Holroyd et al (14) also recognized that FIP1L1-PDGFA is associated with differentiation into both myeloid and lymphoid lineages. Therefore FIP1L1-PDGFRA fusion gene, growth factors and compromised immune system may lead to the co-concurrent bi-lineage malignancies. Besides, the recently studies have confirmed that retrovirus could cause leukemia and lymphoma in reptiles, primates and mammals (15). Furthermore, hematologic neoplasms have been reported to be complications of ATL (16).

From the research, we can see that simultaneous T-LBL and myeloid leukemia are more commonly seen than other subtypes. The reason is still unclear. For T-LBL, combining cytomorphology and flow cytometric immunophenotyping (FCI) enables the accurate and rapid diagnosis (17). The diagnosis of T-LBL is based on the identification of a neoplastic proliferation of small to medium-sized blasts. Blasts express T-cell lineage markers (CD2, CD3, CD4, CD5, CD7, and/or CD8) as well as markers of precursor T lymphoblasts (CD1a, CD34, CD99, and/or TDT) (18). Concurrent T-LBL and CML is likely to misdiagnosed with 8 p11 myeloproliferative syndrome which is characterized in its typical form by the simultaneously or sequentially occurrence of a bcr/abl-negative myeloproliferative disorder and a lymphoma, usually a precursor T lymphoblastic lymphoma (19). The genetic testing can identify.

The prognosis of the simultaneous bi-lineage malignancies is poor with the median survival 15 months in this study. For the treatment, there is not yet consensus with regard to the optimal therapeutic modality due to the limited number of case reports and absence of prospective studies of treatments and outcomes. As we know, in terms of leukemia, hematopoietic stem cell transplantation may be the best choice to reach complete remission. Many studies highlighted the advantages of ASCT to AML (20-22). Meanwhile, some researches show that Allo-geneic BMT treated for young patients is feasible and can result in long-term disease-free survival for advanced LGL or CLL (23). For highly invasive lymphoma, such as T-LBL, allogeneic hematopoietic stem cell transplantation is alternative after reaching complete remission from high dose chemotherapy (24). For bi-lineage hematologic malignancies, chemotherapy is necessary. Withregard to bcr/abl-positive CML, imatinib may improve the survival time even though some reports stated that the targeted drug might lead to the secondary neoplasm. After 

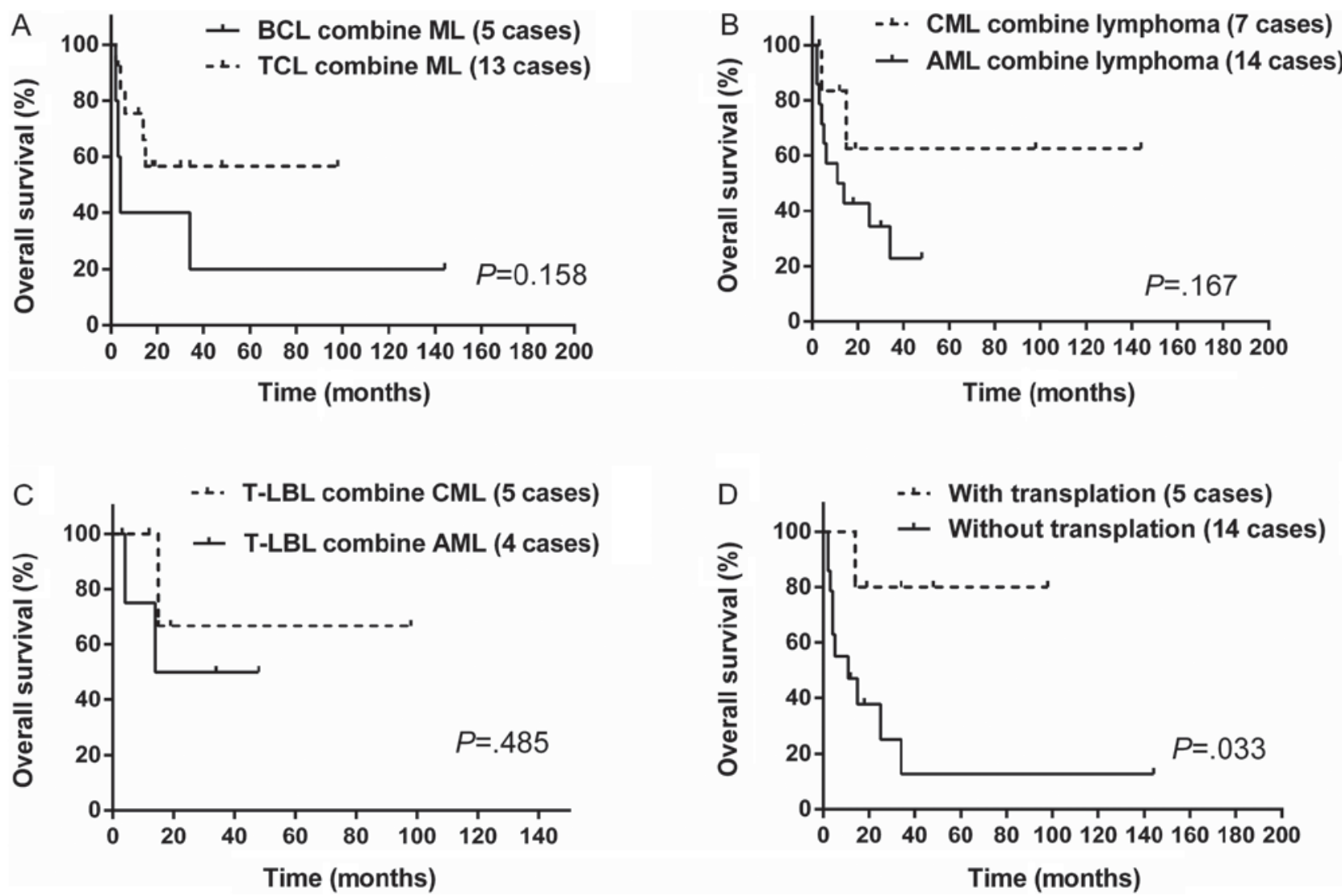

Figure 7. (A-C) The comparison of OS for different kinds of concurrent bi-lineage malignancy and there was no difference in survival. (D) Treatment with HSCT can improve survival compared with that without HSCT. OS, overall survival. HSCT, hematopoietic stem cell transplantation.

complete remission, hematopoietic stem cell transplantation is recommended. From our chart, we concluded that those who were treated with transplantation survived longer than those without transplantation $(\mathrm{P}=0.033)$. Unfortunately, one patient died for graft-versus-host disease (GVHD) after transplantation. It is obvious that the allogeneic hematopoietic stem cell transplantation is good to the lymphoma with myeloid leukemia, but GVHD should be taken high attention. In recent years, immunotherapies paly crucial roles in hematologic neoplasms. CD19-directed CAR-T cells can reach a complete remission rate of $94 \%$ in patients with refractory/relapsed ALL, much higher than that of chemotherapy (25). Bispecific antibodies (BsAbs) can bind simultaneously two different antigens or epitopes, which leads to a wide range of applications including redirecting T cells or NK cells to tumor cells, blocking two different signaling pathways, dual targeting of different disease mediators, and delivering payloads to targeted sites. Immunotherapy has been demonstrating promising clinical results (26). For simultaneous bi-lineage malignancies, immunotherapy may provide a possible remedy.

In conclusion, simultaneous bi-lineage malignancies of myeloid leukemia and lymphomais rarely seen and there is no statistical difference in survival for different types of bi-lineage malignancy in this study. Simultaneous T-NHL and myeloid leukemia is much more than simultaneous B-NHL andmyeloid leukemia, so it is deserved vigilant to the occurence of myeloid leukemia when diagnosed T-NHL. The pathogenesis in unclear and quickly accurate diagnosis is important. For treatment, allogeneic hematopoietic stem cell transplantation may improve survival. More cases are needed to explore pathogenesis and validate our conclusion.

\section{Acknowledgements}

Not applicable.

\section{Funding}

This study was supported by the National Natural Science Foundation of China (grant no. 81570203), the Health Science and Technology Innovation Talents Project of Henan Province (grant no. 2109901), the Key Science and Technology Research Project of Henan province (grant no. 162102310194), the Medical Key Science and Technology Research Project of Henan province (grant no. 201503044).

\section{Availability of data and materials}

All data generated or analyzed during this study are included in this published article.

\section{Authors' contributions}

MZZ has made substantial contributions to the conception and design of the study and critically revised the manuscript. YFS collated and analyzed the patient data and wrote the manuscript. 
XRF was responsible for managing the patients, provided the two cases and revised the manuscript. LZ, LL, XL, XHW and ZCS analyzed and interpreted the data and critically revised the manuscript for important intellectual content. All authors approved the final version of the paper for publication.

\section{Ethics approval and consent to participate}

The study was approved by the Ethics Committee for Scientific Research and Clinical Trials of Zhengzhou University and informed consent was obtained from all patients.

\section{Patient consent for publication}

All patients provided written informed consent for the publication of their data and associated images.

\section{Competing interests}

The authors declare that they have no competing interests.

\section{References}

1. Szumera-Ciećkiewicz A, Gałązka K, Szpor J, Rymkiewicz G, Jesionek-Kupnicka D, Gruchała A, Ziarkiewicz-Wróblewska B, Poniatowska-Broniek G, Demczuk S and Prochorec-Sobieszek M: Distribution of lymphomas in Poland according to World Health Organization classification: Analysis of 11718 cases from National Histopathological Lymphoma Register project-the Polish Lymphoma Research Group study. Int J Clin Exp Pathol 7: 3280-3286, 2014.

2. Zámecníková A, Vranovský A and Hlavcák P: Coexistence of Philadelphia-positive chronic granulocytic leukemia and diffuse large B-cell lymphoma at initial diagnosis. Leuk Lymphoma 43: 429-431, 2002.

3. Shen ZL, Yin LF, Mao WW, Liang J and Yang L: Philadelphia chromosome-negative non-Hodgkin's lymphoma occurring in Philadelphia chromosome-positive chronic myeloid leukemia: A case report and literature review. Oncol Lett 11: 2909-2912, 2016.

4. Eichenauer DA, Thielen I, Haverkamp H, Franklin J, Behringer K, Halbsguth T, Klimm B, Diehl V, Sasse S, Rothe A, et al: Therapy-related acute myeloid leukemia and myelodysplastic syndromes in patients with Hodgkin lymphoma: A report from the German Hodgkin Study Group. Blood 123: 1658-1664, 2014

5. Roberts E III, Oncale M, Safah H and Schmieg J: Therapy-related $\mathrm{T} /$ myeloid mixed phenotype acute leukemia in a patient treated with chemotherapy for cutaneous diffuse large B cell lymphoma. J La State Med Soc 168: 16-20, 2016.

6. Lam CJ, Curtis RE, Dores GM, Engels EA, Caporaso NE, Polliack A, Warren JL, Young HA, Levine PH, Elmi AF, et al: Risk factors for second acute myeloid leukemia/myelodysplastic syndrome among survivors of non-Hodgkin lymphoma. Leukemia 30: 1187-1190, 2016.

7. Bhatt VR, Giri S, Verma V, Dahal S, Shah BK, Pathak R, Bociek RG, Vose JM and Armitage JO: Secondary acute myeloid leukemia in survivors of Hodgkin lymphoma. Future Oncol 12: $1565-1575,2016$

8. International Non-Hodgkin's Lymphoma Prognostic Factors Project: A predictive model for aggressive non-Hodgkin's lymphoma. N Engl J Med 329: 987-994, 1993.

9. Abe Y, Takatsuki H, Okada Y, Saito A, Kimura T and Nishimura J: Mucosa-associated lymphoid tissue type lymphoma of the gallbladder associated with acute myeloid leukemia. Intern Med 38: 442-444, 1999.

10. Van Crombrugge L, De Vos G, Vanclooster C, Lemmerling M and Kerre T: The simultaneous appearance of a nasal natural killer-cell lymphoma and acute myelogenous leukemia. B-ENT 8: 49-52, 2012.

11. Tsukasaki K, Koba T, Iwanaga M, Murata K, Maeda T, Atogami S, Nakamura H, Yamada Y, Kamihira S and Tomonaga M: Possible association between adult T-cell leukemia/lymphoma and acute myeloid leukemia. Cancer 82: 488-494, 1998.
12. Metzgeroth G, Walz C, Score J, Siebert R, Schnittger S, Haferlach C, Popp H, Haferlach T, Erben P, Mix J, et al: Recurrent finding of the FIP1L1-PDGFRA fusion gene in eosinophilia-associated acute myeloid leukemia and lymphoblastic T-cell lymphoma. Leukemia 21: 1183-1188, 2007.

13. Chang H, Chuang WY, Sun CF and Barnard MR: Concurrent acute myeloid leukemia and $\mathrm{T}$ lymphoblastic lymphoma in a patient with rearranged PDGFRB genes. Diagn Pathol 7: 19, 2012.

14. Holroyd A, Cross NC and Macdonald DH: The two faces of myeloproliferative neoplasms: Molecular events underlying lymphoid transformation. Leuk Res 35: 1279-1285, 2011.

15. Melo JV and Deininger MW: Biology of chronic myelogenous leukemia-signaling pathways of initiation and transformation. Hematol Oncol Clin North Am 18: 545-568, vii-viii, 2004.

16. Tsukasaki K, Fujimoto T, Hata T, Yamada Y, Kamihira S and Tomonaga M: Concomitant complete remission of APL and smoldering ATL following ATRA therapy in a patient with the two diseases simultaneously. Leukemia 9: 1797-1798, 1995.

17. Bhaker P, Das A, Rajwanshi A, Gautam U, Trehan A, Bansal D, Varma N and Srinivasan R: Precursor T-lymphoblastic lymphoma: Speedy diagnosis in FNA and effusion cytology by morphology, immunochemistry, and flow cytometry. Cancer Cytopathol 123: 557-565, 2015.

18. Jain N, Lamb AV, O'Brien S, Ravandi F, Konopleva M, Jabbour E, Zuo Z, Jorgensen J, Lin P, Pierce S, et al: Early T-cell precursor acute lymphoblastic leukemia/lymphoma (ETP-ALL/LBL) in adolescents and adults: A high-risk subtype. Blood 127: 1863-1869, 2016.

19. Goradia A, Bayerl M and Cornfield D: The 8p11 myeloproliferative syndrome: Review of literature and an illustrative case report. Int J Clin Exp Pathol 1: 448-456, 2008.

20. Vellenga E, van Putten W, Ossenkoppele GJ, Verdonck LF, Theobald M, Cornelissen JJ, Huijgens PC, Maertens J, Gratwohl A, Schaafsma R, et al: Autologous peripheral blood stem cell transplantation for acute myeloid leukemia. Blood 118: 6037-6042, 2011.

21. Gorin NC, Labopin M, Reiffers J, Milpied N, Blaise D, Witz F, de Witte T, Meloni G, Attal M, Bernal T, et al: Higher incidence of relapse in patients with acute myelocytic leukemia infused with higher doses of CD34+ cells from leukapheresis products autografted during the first remission. Blood 116: 3157-3162, 2010.

22. Gorin NC, Labopin M, Blaise D, Reiffers J, Meloni G, Michallet M, de Witte T, Attal M, Rio B, Witz F, et al: Higher incidence of relapse with peripheral blood rather than marrow as a source of stem cells in adults with acute myelocytic leukemia autografted during the first remission. J Clin Oncol 27: 3987-3993, 2009.

23. Toze CL, Shepherd JD, Connors JM, Voss NJ, Gascoyne RD, Hogge DE, Klingemann HG, Nantel SH, Nevill TJ, Phillips GL, et al: Allogeneic bone marrow transplantation for low-grade lymphoma and chronic lymphocytic leukemia. Bone Marrow Transplant 25: 605-612, 2000.

24. Haioun C, Mounier N, Emile JF, Ranta D, Coiffier B, Tilly H, Récher C, Fermé C, Gabarre J, Herbrecht R, et al: Rituximab versus observation after high-dose consolidative first-line chemotherapy with autologous stem-cell transplantation in patients with poor-risk diffuse large B-cell lymphoma. Ann Oncol 20: 1985-1992, 2009.

25. Wei G, Ding L, Wang J, Hu Y and Huang H: Advances of CD19-directed chimeric antigen receptor-modified T cells in refractory/relapsed acute lymphoblastic leukemia. Exp Hematol Oncol 6: 10, 2017.

26. Wei G, Wang J, Huang $H$ and Zhao Y: Novel immunotherapies for adult patients with B-lineage acute lymphoblastic leukemia. J Hematol Oncol 10: 150, 2017.

27. Kapadia SB and Kaplan SS: Simultaneous occurrence of non-Hodgkin's lymphoma and acute myelomonocytic leukemia. Cancer 38: 2557-2560, 1976.

28. Youness E, Ahearn MJ and Drewinko B: Simultaneous occurrence of non-Hodgkin's lymphoma and spontaneous acute granulocytic leukemia. Am J Clin Pathol 70: 415-420, 1978.

29. Ramji S, Rusia U and Basu TK: Simultaneous occurrence of a chronic myeloid leukemia and a malignant T-cell lymphoma. Indian Pediatr 25: 566-568, 1988.

30. Ohtsu T, Tobinai K, Minato K, Mukai K, Kagami Y, Miwa M, Arai $\mathrm{C}$ and Shimoyama M: Concurrent adult T-cell leukemia and acute myeloblastic leukemia. Jpn J Clin Oncol 18: 33-41, 1988. 
31. Morales E, Bancalari G, Fahrenkrog AM and Rossle A: Chronic myeloid leukemia and non Hodgkin lymphoma in the same patient. Clinical case. Rev Med Chil 127: 1105-1107, 1999 (In Spanish).

32. Montefusco E, Fazi F, Cordone I, Ariola C, Nanni M, Spadea A, Spiriti MA, Fenu S, Mandelli F and Petti MC: Molecular remission following high-dose hydroxyurea and fludarabine plus cytarabine in a patient with simultaneous acute myeloid leukemia and low-grade lymphoma. Leuk Lymphoma 40: 671-674, 2001.

33. Au WY, Ma SK, Wan TS, Wang EP, Lau TC and Kwong YL: Concurrent mediastinal B cell lymphoma and chronic myeloid leukemia with an unusually favorable response to chemotherapy. Leuk Lymphoma 44: 535-538, 2003.

34. Lamb LS Jr, Neuberg R, Welsh J, Best R, Stetler-Stevenson M and Sorrell A: T-cell lymphoblastic leukemia/lymphoma syndrome with eosinophilia and acute myeloid leukemia. Cytometry B Clin Cytom 65: 37-41, 2005.

35. Capovilla M, Cayuela JM, Bilhou-Nabera C, Gardin C, Letestu R, Baran-Marzak F, Fenaux P and Martin A: Synchronous FIP1L1-PDGFRA-positive chronic eosinophilic leukemia and T-cell lymphoblastic lymphoma: A bilineal clonal malignancy. Eur J Haematol 80: 81-86, 2008.

36. Li YH, Xiao Y and Jiang ZJ: Childhood lymphoblastic lymphoma with acute myeloid leukemia: A case report and literature review. Zhonghua Xue Ye Xue Za Zhi 32: 127-128, 2011 (In Chinese).
37. Sharkunov NN, Moiseyeva TN, Zybunova EE, Vinogradova OY and Kravchenko SK: Successful treatment for Hodgkin's lymphoma in a female patient with $\mathrm{Ph}+$ chronic myeloid leukemia. Ter Arkh 84: 71-74, 2012 (In Russian).

38. Wan DM, Zhang SP and Zhang C: Haploidentical hematopoietic stem cell transplantation for treatment of T-lymphoblastic lymphoma with chronic myeloid leukemia: A case report and literature review. Zhonghua Xue Ye Xue Za Zhi 33: 227-228, 2012 (In Chinese).

39. Kunitomi A, Kotani S, Ukyo N, Ono K, Nakamine H and Nohgawa M: Epstein-Barr virus-positive diffuse large B-cell lymphoma of the elderly complicated by the onset of acute myeloid leukemia. Intern Med 53: 51-56, 2014.

40. Dong HJ, Wu W, Wang JH, Zhu HF, Gao S, Hou LP and Bai QX: Acute myeloid leukemia complicated with complex karyotypes and T-lymphoblastic lymphoma: A case report. Zhonghua Xue Ye Xue Za Zhi 37: 237, 2016 (In Chinese).

41. Dai Y, Shuai X, Kuang P, Wang L, Liu T and Niu T: Philadelphia chromosome with acute myeloid leukemia and concurrent large B cell lymphoma of different origins: A case report. Oncol Lett 13: 1189-1193, 2017.

(i) $\Theta$ This work is licensed under a Creative Commons Attribution-NonCommercial-NoDerivatives 4.0 International (CC BY-NC-ND 4.0) License. 